\title{
Prognostic value of nuclear FBI-1 in patients with rectal cancer with or without preoperative radiotherapy
}

\author{
CHAO-JIE WANG ${ }^{1-3}$, CHU-RUI CHAO $^{1}$, HUI-MIN LIU ${ }^{1}$, YAN-YAN ZHU ${ }^{1}$, GUNNAR ADELL $^{2,3}$, \\ INGVAR JARLSFELT ${ }^{4}$, HONG ZHANG ${ }^{5}$ and XIAO-FENG SUN ${ }^{2,3}$
}

\begin{abstract}
${ }^{1}$ Department of Oncology, Henan Provincial People's Hospital \& People's Hospital of Henan University, Zhengzhou, Henan 450003, P.R. China; Departments of ${ }^{2}$ Oncology and ${ }^{3}$ Clinical and Experimental Medicine, Linköping University, Linköping SE-58183; ${ }^{4}$ Department of Pathology, Ryhov Hospital, Jönköping SE-55111;

${ }^{5}$ Department of Medical Sciences, Örebro University, Örebro SE-70182, Sweden
\end{abstract}

Received May 10, 2019; Accepted June 6, 2019

DOI: $10.3892 / \mathrm{ol} .2019 .10890$

\begin{abstract}
Factor that binds to the inducer of short transcripts of the human immunodeficiency virus-1 (FBI-1) represents as a crucial gene regulator in colorectal cancer; however, the correlation between FBI-1 and preoperative radiotherapy (RT) in rectal cancer (RC) has not yet been reported. The aim was to detect FBI-1 expression in patients with RC with or without RT, by immunohistochemistry and quantitative polymerase chain reaction, and to analyze its association with clinicopathological features and response to RT. The results from immunohistochemistry analysis $(n=139)$ and reverse transcription-quantitative polymerase chain reaction $(\mathrm{n}=55)$ demonstrated that FBI-1 was overexpressed in patients with RC, whether they had received preoperative RT or not. Subsequently, the association between FBI-1 expression, and the clinicopathological features and response to RT in patients with RC was analyzed. Cytoplasmic FBI-1 was upregulated in non-RT $(\mathrm{n}=77)$ and $\mathrm{RT}(\mathrm{n}=62)$ groups $(17.7$ vs. $74.0 \%, \mathrm{P}<0.001$; 41.1 vs. $69.4 \%, \mathrm{P}=0.002$, respectively) of patients with $\mathrm{RC}$ compared with normal mucosa. However, nuclear FBI-1 was downregulated ( 75.8 vs. $22.1 \%, \mathrm{P}<0.001 ; 83.9$ vs. $35.5 \%$, $\mathrm{P}<0.001$, respectively) in both groups. RT had no significant effect on FBI-1 expression in RC tissues. Furthermore, nuclear FBI-1 was positively associated with tumor-node-metastasis stage and distant recurrence $(\mathrm{P}=0.003$ and $\mathrm{P}=0.010$, respectively). In patients with stage I, II or III RC, higher nuclear
\end{abstract}

Correspondence to: Dr Chao-Jie Wang, Department of Oncology, Henan Provincial People's Hospital and People's Hospital of Henan University, 7 Weiwu Road, Zhengzhou, Henan 450003, P.R. China E-mail: zzwangcj@henu.edu.cn

Professor Xiao-Feng Sun, Department of Oncology, Linköping University, 10 Linnegatan, Linköping SE-58183, Sweden E-mail: xiao-feng.sun@liu.se

Key words: factor that binds to the inducer of short transcripts of the human immunodeficiency virus-1, rectal cancer, prognosis, preoperative radiotherapy, biomarker
FBI-1 expression was associated with poorer disease-free survival [hazard ratio $(\mathrm{HR})=1.934,95 \%$ confidence interval (CI): 1.055-3.579, $\mathrm{P}=0.033$ ] and overall survival $(\mathrm{HR}=2.174$, 95\% CI: $1.102-4.290, \mathrm{P}=0.025)$, independently of sex, age, growth pattern, differentiation and RT. In addition, FBI-1 was positively correlated with numerous biological factors, including p73 [Spearman's correlation coefficient $\left(r_{s}\right)=0.332$, $\mathrm{P}=0.007]$, lysyl oxidase $\left(\mathrm{r}_{\mathrm{s}}=0.234, \mathrm{P}=0.043\right)$, Wrap53 $\left(r_{s}=-0.425, P=0.0002\right)$ and peroxisome proliferator-activated receptor $\delta\left(r_{s}=-0.294, P=0.026\right)$. In conclusion, the present study demonstrated that nuclear FBI-1 was an independent prognostic factor in patients with $\mathrm{RC}$ and correlated with numerous biological factors, which indicated that it may have multiple roles in $\mathrm{RC}$.

\section{Introduction}

Factor that binds to the inducer of short transcripts of the human immunodeficiency virus-1 (FBI-1) plays an important role in gene expression. FBI-1 is also known as leukemia/lymphoma-related factor or POK erythroid myeloid ontogenic factor (pokemon) (1-3). FBI-1 is an essential regulator of genes, and previous studies have reported that FBI-1 is overexpressed in various types of cancer, including ovarian cancer, hepatocellular carcinoma (HCC), non-small-cell lung cancer, endometrial carcinoma, nasopharyngeal carcinoma, prostate cancer and breast cancer (4-11). Although most cancers exhibit FBI-1-overexpression, a previous study reported that FBI-1 is significantly downregulated in oral squamous cell carcinoma (12), which indicates its complex role in tumorigenesis.

Previous studies have investigated the protein and mRNA expression of FBI-1 in small sample size populations of colorectal cancer (CRC; 46-66 CRC samples). The results demonstrated that FBI-1 is overexpressed in CRC tissues compared with normal mucosa and that FBI-1-silencing inhibits the proliferation, cell cycle and apoptosis of CRC cells $(13,14)$. In addition, higher FBI-1 expression is associated with lymph node metastasis and higher Duke's stage (14). Furthermore, a study reported that low-dose radiation under hypoxic conditions downregulates FBI-1 expression in rat pheochromocytoma PC12 cells (15). Preoperative radiotherapy 
(RT) is recommended for patients with locally advanced RC and is associated with a decreased rate of local recurrence and an improved survival $(16,17)$. Although numerous studies have reported that FBI-1 is an important gene regulator in CRC $(13,14)$, the association of FBI-1 expression with the prognosis and $\mathrm{RT}$ of patients with $\mathrm{RC}$ require further investigation.

The present study used immunohistochemistry and reverse transcription-quantitative polymerase chain reaction (RT-qPCR) to determine whether FBI-1 was associated with the response to RT, and with clinicopathological variables and biological factors, including p53, Wrap53, p73, peroxisome proliferator-activated receptor $\delta$ (PPAR $\delta$ ), lysyl oxidase (LOX) and $\mathrm{Ki}-67$, in patients with RC.

\section{Materials and methods}

Patient samples. Samples were collected from a total of 139 patients who underwent RC resection planned between March 1987 and February 1990 and were recruited at the Swedish clinical trial (86151) of preoperative RT. Patients included 85 men and 54 women, with an age range of 36-85 years (mean, 66 years old). Patients were randomly assigned either to 1 week of preoperative RT followed by surgery within the next week (RT + surgery group), or surgery with no preoperative RT (surgery alone group).

$\mathrm{RC}$ tissues following resection were immediately fixed, paraffin-embedded and stored at $4^{\circ} \mathrm{C}$ at the Linköping University until further use. These formalin-fixed paraffin-embedded sections were used for immunohistochemistry (IHC). IHC was also performed on 118 distant normal mucosa specimens taken from the resection margins, which were histologically free from tumor cells (105 normal mucosa samples had matched primary tumors from the same patient, whereas 13 samples did not have matched tumor samples). Amongst the 139 patients, 77 underwent surgery only and 62 received RT followed by tumor resection. RT was administered as 25 Gy in five fractions within a median of 7 days (range, 4-12 days). Surgery was then performed at a median of 3 days (range, 0-11 days) following RT. Information on tumor-node-metastasis (TNM) stage (American Joint Committee on Cancer staging manual, 4th edition) (18), differentiation, local and distant recurrence, disease-free survival (DFS) and overall survival (OS) was obtained from surgical and pathological hospital records. Tumor differentiation was graded as improved (including well-and moderately differentiated tumors) or poorer (including poor, mucinous and signet-ring cell tumors). The mean follow-up period was 100 months (range, 0-309 months). The characteristics of patients and tumors are presented in Table I.

Additional samples were collected from another cohort of 55 patients with RC treated at the Linköping University hospital between April 1990 and February 2003. Patients were aged between 51-88 years old, comprising 35 men and 20 females, and had not received any treatment prior to RC resection. These samples were collected to detect FBI-1 mRNA expression. For each patient, samples from the primary tumor and corresponding normal mucosa were collected. All specimens were immediately flash-frozen in liquid nitrogen following $\mathrm{RC}$ resection and stored at $-80^{\circ} \mathrm{C}$.

Expression of p53, Wrap53, p73, PPARd, LOX and $\mathrm{Ki}-67$ were examined by IHC on the normal mucosa and
RC samples from the non-RT and RT groups, as previously described (19-22).

The present study was approved by the Medical Ethics Committee of Linköping University approval, and written informed consent was obtained from each patient.

IHC. FBI-1 IHC was performed on 5- $\mu \mathrm{m}$ paraffin-embedded tissue sections. Sections were incubated at $60^{\circ} \mathrm{C}$ for $12 \mathrm{~h}$ prior to being deparaffinized in xylene and hydrated in descending concentrations of ethanol $(99.5 \%$, for $5 \mathrm{~min}$ twice; $95 \%$, for $5 \mathrm{~min} ; 70 \%$, for $5 \mathrm{~min}$ ) at room temperature. Sections were placed in Tris-EDTA buffer $(\mathrm{pH}, 9.0)$, heated to $125^{\circ} \mathrm{C}$ for $30 \mathrm{sec}$ and cooled down to $90^{\circ} \mathrm{C}$ for $10 \mathrm{sec}$ in a high-pressure cooker to allow antigen retrieval. Sections were then washed in PBS ( $\mathrm{pH}$ 7.4). Endogenous peroxidase activity of the sections was blocked with $3 \%$ hydrogen peroxide dissolved in $99.9 \%$ methanol for $10 \mathrm{~min}$ at room temperature. Sections were washed three times with PBS. Blocking of non-specific interactions was then performed with $1.5 \%$ blocking serum (Dako; Agilent Technologies, Inc.) in PBS for $10 \mathrm{~min}$ at room temperature. Sections were incubated overnight at $4^{\circ} \mathrm{C}$ with the primary antibody against FBI-1 (cat. no. ab70208; Abcam) diluted in antibody diluent (1:200; Dako; Agilent Technologies, Inc.). The sections were then incubated with a horseradish peroxidase-conjugated anti-rabbit secondary antibody (1:100; cat. no. P0397; Dako; Agilent Technologies, Inc.) for $45 \mathrm{~min}$ at $37^{\circ} \mathrm{C}$ and stained with 3,3'-diaminobenzidine tetrahydrochloride (Dako; Agilent Technologies, Inc.) at room temperature for $5 \mathrm{~min}$. The sections were eventually counterstained with haematoxylin. Immunoglobulin G1 (1:800; cat. no. SAB5500149; Sigma-Aldrich; Merck KGaA) was used as negative control.

Sections were examined with a light microscope (CX43; Olympus Corporation) at x400 magnification and scored independently by Dr Wang and Professor Zhang, who were double-blinded to the clinicopathological and biological data (including p53, Wrap53, p73, PPARS, LOX and Ki-67 data). The nuclear staining intensity in epithelial or tumor cells was scored as negative, weak, moderate or strong staining, for $<5,5-24,25-50$ or $>50 \%$ cells positively stained, respectively. The staining patterns were recorded as cytoplasmic or nuclear. Cases of scoring discrepancy were re-evaluated individually until the two investigators agreed on the scoring. The remaining cases were re-examined by the two investigators together using a dual-headed microscope in order to reach a consensus score. To avoid artifacts, areas with necrosis or poor morphology and sections margins were excluded.

$R T-q P C R$. The relative expression level of FBI-1 was determined by RT-qPCR in a 7900HT Fast Real-Time PCR system (Applied Biosystems; Thermo Fisher Scientific, Inc.) and normalized to GAPDH. Primers and probes were included in the TaqMan ${ }^{\mathrm{TM}}{ }^{\circledR}$ Gene Expression assays for FBI-1 (Hs00252415_s1) and GAPDH (4352934E; both Applied Biosystems; Thermo Fisher Scientific, Inc.).

According to the manufacturer's instructions, total RNA of RC and the corresponding normal mucosa samples was extracted using the TRIzol reagent (Sigma-Aldrich; Merck $\mathrm{KGaA}$ ) and RNeasy extraction kit (Qiagen, Inc.). The concentration, purity, and integrity of RNA were measured by 
Table I. Characteristics of patients with rectal cancer.

\begin{tabular}{|c|c|c|c|c|c|}
\hline \multirow[b]{2}{*}{ Characteristics } & \multicolumn{2}{|c|}{ Non-radiotherapy } & \multicolumn{2}{|c|}{ Radiotherapy } & \multirow[b]{2}{*}{ P-value } \\
\hline & Number & $\%$ & Number & $\%$ & \\
\hline Sex & & & & & 0.465 \\
\hline Male & 45 & 58.4 & 40 & 64.5 & \\
\hline Female & 32 & 41.6 & 22 & 35.5 & \\
\hline Age (years) & & & & & 0.929 \\
\hline$\leq 66$ & 28 & 36.4 & 23 & 37.1 & \\
\hline$>66$ & 49 & 63.6 & 39 & 62.9 & \\
\hline TNM stage & & & & & 0.270 \\
\hline I & 20 & 26 & 17 & 27.4 & \\
\hline II & 19 & 24.7 & 22 & 35.5 & \\
\hline III & 34 & 44.1 & 18 & 29.0 & \\
\hline IV & 4 & 5.2 & 5 & 8.1 & \\
\hline Differentiation & & & & & 0.765 \\
\hline High & 2 & 2.6 & 1 & 1.6 & \\
\hline Moderate & 61 & 79.2 & 47 & 75.8 & \\
\hline Poor & 14 & 18.2 & 14 & 22.6 & \\
\hline Number of tumors & & & & & 0.392 \\
\hline Single & 64 & 83.1 & 51 & 82.3 & \\
\hline Multiple $^{\mathrm{a}}$ & 11 & 14.3 & 11 & 17.7 & \\
\hline Unknown & 2 & 2.6 & 0 & 0 & \\
\hline Resection margin & & & & & 0.677 \\
\hline Negative & 72 & 93.5 & 59 & 95.2 & \\
\hline Positive & 5 & 6.5 & 3 & 4.8 & \\
\hline
\end{tabular}

${ }^{\mathrm{a}}$ Other colorectal cancer and/or other tumor type prior to rectal cancer. TNM, tumor-node-metastasis.

NanoDrop (Thermo Fisher Scientific, Inc.) and Bioanalyzer Agilent (Agilent Technologies, Inc.). RT was conducted according to the manufacturer's protocol of the High Capacity cDNA Reverse Transcription kit (Applied Biosystems; Thermo Fisher Scientific, Inc.). The relative expression levels of FBI-1 were determined by RT-qPCR and normalized to GAPDH. The PCR mix included $1 \mu \mathrm{l}$ RT product, $7.5 \mu \mathrm{l}$ TaqMan Fast Universal PCR Master mix (2X No AmpErase UNG), $0.75 \mu 1$ 2X TaqMan gene Assay and $5.75 \mu 1$ nuclease-free water. The reactions were incubated in a 96 -well plate at $95^{\circ} \mathrm{C}$ for $20 \mathrm{sec}$, followed by 40 circles of $95^{\circ} \mathrm{C}$ for $3 \mathrm{sec}$ and $60^{\circ} \mathrm{C}$ for $30 \mathrm{sec}$. In addition, double-distilled $\mathrm{H}_{2} \mathrm{O}$ was analyzed as the no-template control for every plate. All reactions, including the no-template control, were performed in triplicates. The relative expression level of FBI-1 was calculated using the $2^{-\Delta \Delta \mathrm{Cq}}$ method (23).

Statistical analysis. The values for FBI-1 mRNA level were transformed to $\log _{2}$ values and data were normally distributed. The data are expressed as the mean \pm standard deviation of at least three independent experiments. Paired t-test or McNemar's test were used to determine the differences in FBI-1 mRNA or protein level between normal mucosa and primary $\mathrm{RC}$ respectively. $\chi 2$ test was used to analyze unpaired data, and to determine the association between
FBI-1 protein level in primary $\mathrm{RC}$ and clinicopathological variables. Spearman's correlation test was used to analyze the correlations between the protein expression of FBI-1 and other molecular markers, including p53, Wrap53, p73, PPARס, LOX and Ki-67, from previous studies performed on the same samples (19-22). Cox's proportional hazard model was used to determine the association between FBI-1 protein expression and patient survival. The Kaplan-Meier method was used to generate survival curves. All statistical analyses were carried out by using STATISTICA software package (version 7.0; StatSoft, Inc.). $\mathrm{P}<0.05$ was considered to indicate a statistically significant difference.

\section{Results}

Expression of FBI-1 in normal mucosa and RC samples in non-RT and RT groups. FBI-1 protein expression was detected in the cytoplasm and nucleus of normal mucosa and primary cancer cells (Fig. 1). The intensity in epithelial cells or tumor cells was scored as negative, weak (light yellow), moderate (yellow brown) and strong staining (brown). The negative control showed no staining (Fig. 1A). Moderate cytoplasmic and strong nuclear staining of FBI-1 was observed in normal mucosa (Fig. 1B) and primary tumor (Fig. 1C). Strong cytoplasmic staining of FBI-1 was observed in the primary 

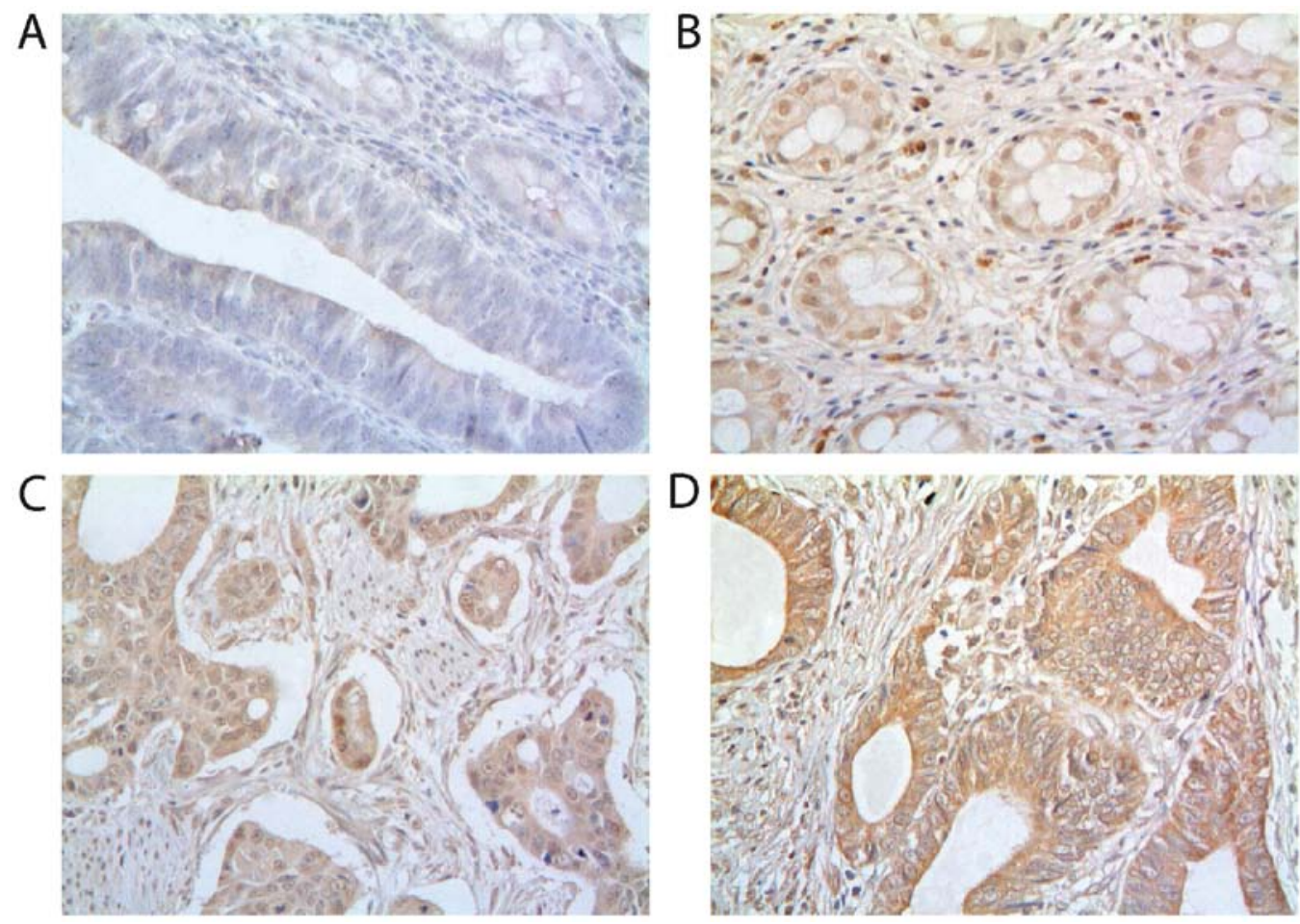

Figure 1. FBI-1 protein was detected in the cytoplasm and nucleus of normal mucosa and primary tumor (A) Negative control. (B) Moderate cytoplasmic and strong nuclear staining of FBI-1 in normal mucosa. (C) Moderate cytoplasmic and nuclear staining of FBI-1 in the primary tumor. (D) Strong cytoplasmic staining of FBI-1 in the primary tumor. Magnification, x400. FBI-1, factor that binds to the inducer of short transcripts of the human immunodeficiency virus-1.

A

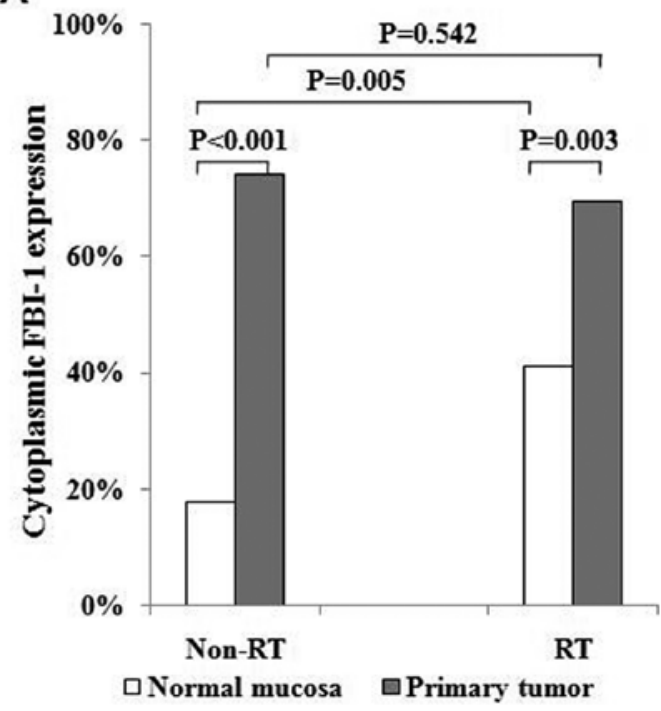

B

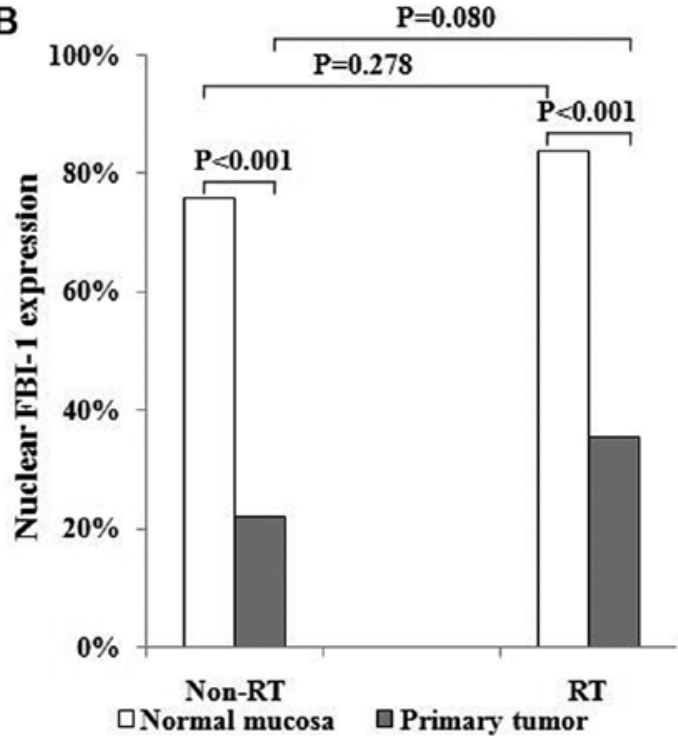

Figure 2. Frequency of high cytoplasmic and nuclear expression of FBI-1 in normal mucosa, primary tumor with or without preoperative RT. (A) Cytoplasmic FBI-1 expression was significantly increased in the primary tumor compared with normal mucosa. (B) FBI-1 expression in the nucleus was significantly decreased in the tumor tissues compared with normal mucosa. FBI-1, factor that binds to the inducer of short transcripts of the human immunodeficiency virus-1; RT, radiotherapy.

tumor (Fig. 1D). Subsequently, samples were separated into subgroups based on the expression level of FBI-1, including low-expression (negative and weak staining intensity) and high-expression (moderate and strong staining intensities). Cytoplasmic staining of FBI-1 in RC samples was significantly upregulated in the non-RT and RT groups (17.7 vs. $74.0 \%$; 41.1 vs. $69.4 \%$; Fig. 2 A) compared with the corresponding normal mucosa. However, nuclear staining of FBI-1 was significantly downregulated in the non-RT and RT groups of RC samples ( 75.8 vs. 22.1 and 83.9 vs. $35.5 \%$, respectively; Fig. 2B) compared with the corresponding normal mucosa. Furthermore, RT resulted in markedly increased FBI-1 expression in the cytoplasm of normal mucosa compared with non-RT (41.1 vs. $17.7 \%$, respectively; $\mathrm{P}=0.005$; Fig. $2 \mathrm{~A}$ ), but not 
Table II. Association between nuclear expression of FBI-1 and clinicopathological characteristics of patients with rectal cancer.

\begin{tabular}{|c|c|c|c|}
\hline \multirow[b]{2}{*}{ Characteristics } & \multicolumn{2}{|c|}{ Nuclear expression } & \multirow[b]{2}{*}{$\mathrm{P}$-value } \\
\hline & Low $(\%)$ & High (\%) & \\
\hline Sex & & & 0.222 \\
\hline Male & $58(68.2)$ & $27(31.8)$ & \\
\hline Female & $42(77.8)$ & $12(22.2)$ & \\
\hline Age (years) & & & 0.292 \\
\hline$\leq 66$ & $34(66.7)$ & $17(33.3)$ & \\
\hline$>66$ & $66(75.0)$ & $22(25.0)$ & \\
\hline TNM stage & & & 0.003 \\
\hline $\mathrm{I}+\mathrm{II}$ & $64(82.1)$ & $14(17.9)$ & \\
\hline III+IV & $36(59.0)$ & $25(41.0)$ & \\
\hline Differentiation & & & 0.139 \\
\hline High/moderate & $83(74.8)$ & $28(25.2)$ & \\
\hline Poor & $17(60.7)$ & $11(39.3)$ & \\
\hline GP & & & 0.070 \\
\hline Expanding & $64(78.0)$ & $18(22.0)$ & \\
\hline Invasive & $23(62.2)$ & $14(37.8)$ & \\
\hline LR & & & 0.544 \\
\hline No & $83(70.9)$ & $34(29.1)$ & \\
\hline Yes & $17(77.3)$ & $5(22.7)$ & \\
\hline DR & & & 0.010 \\
\hline No & $65(80.2)$ & $16(19.8)$ & \\
\hline Yes & $35(60.3)$ & $23(39.7)$ & \\
\hline
\end{tabular}

DR, distance recurrence; GP, growth pattern; LR, local recurrence.

in the nucleus (83.9 vs. $75.8 \%$, respectively; $\mathrm{P}=0.278$; Fig. $2 \mathrm{~B}$ ). In addition, cytoplasmic and nuclear staining of FBI-1 in RC cells were similar between the non-RT and RT groups (cytoplasmic, 74.0 vs. $69.4 \%$; $\mathrm{P}=0.542$; Fig. $2 \mathrm{~A}$; nuclear, 22.1 vs. $35.5 \%$; $\mathrm{P}=0.080$; Fig. 2B). The non-RT and RT groups were therefore combined for further analyses.

In the additional cohort of 55 patients with RC, FBI-1 mRNA expression was significantly upregulated in RC tissues $(2.491 \pm 0.257$ vs. $1.325 \pm 0.270 ; \mathrm{P}<0.0001$; Fig. 3$)$ compared with the corresponding normal mucosa.

Association between nuclear FBI-1 expression and clinicopathological characteristics. The present study analyzed the association between cytoplasmic and nuclear FBI-1 expression and clinicopathological characteristics, including sex, age, RC stage, differentiation, growth pattern and local and distant recurrence. As presented in Table II, the high expression of nuclear FBI-1 was significantly higher in patients with stage III+IV RC compared with patients with stage I+II RC (41.0 vs. $17.9 \%$, respectively; $\mathrm{P}=0.003$ ). Furthermore, nuclear FBI-1 expression in patients with distant recurrence exhibited a higher positive staining compared with patients without distant recurrence (39.7 vs. 19.8\%, respectively; $\mathrm{P}=0.010)$. In addition, FBI-1 expression exhibited a

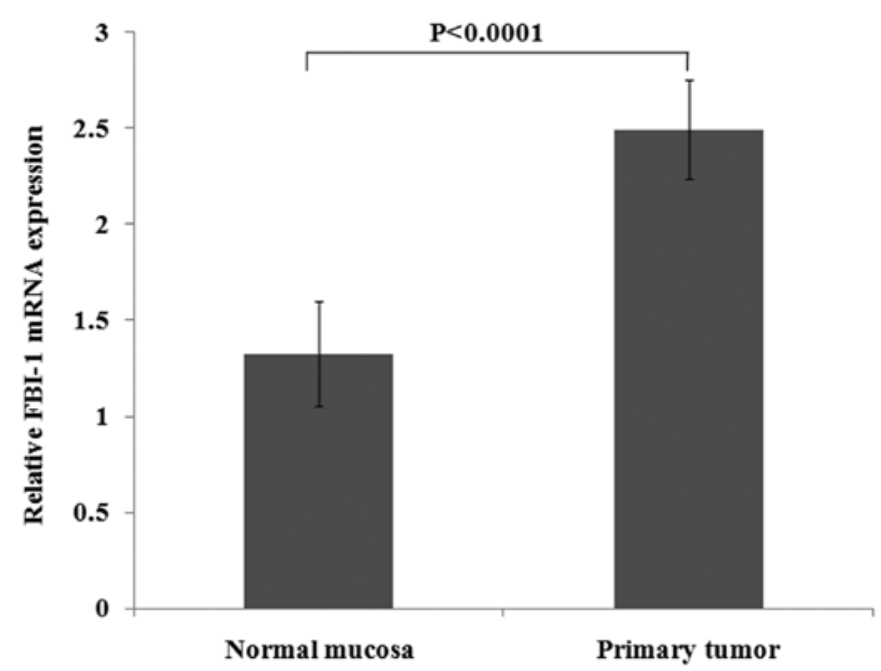

Figure 3. FBI-1 mRNA expression in normal mucosa and primary tumor. Compared with the corresponding normal mucosa, FBI-1 mRNA expression was significantly upregulated in primary tumor samples. FBI-1, factor that binds to the inducer of short transcripts of the human immunodeficiency virus-1.

trend for higher expression in patients with $\mathrm{RC}$ and invasive growth pattern, compared with patients with RC and expanding growth pattern (37.8 vs. $22 \%$, respectively; $\mathrm{P}=0.070)$. Nuclear FBI-1 expression was not associated with other characteristics analyzed in the present study, including sex, age, differentiation and local recurrence.

Cytoplasmic FBI-1 expression and FBI-1 mRNA expression were also compared to the clinicopathological characteristics; however, no significant association was observed (data not shown).

Nuclear FBI-1 expression as a prognostic factor in primary cancer. Among the 139 patients with RC included in the present study, 37, 41, 52 and 9 had stage I, II, III and IV RC, respectively. The present study conducted a survival analysis that only included patients with stage I, II and III RC, due to the poor survival of patients with stage IV RC. The results demonstrated that, in patients with stage I, II or III RC, upregulated nuclear FBI-1 expression in RC samples correlated with poorer DFS and OS times ( $\mathrm{P}=0.017$ and $\mathrm{P}=0.029$, respectively; Fig. $4 \mathrm{~A}$ and $\mathrm{B})$.

A subgroup analysis in patients with TNM stages I, II or III $\mathrm{RC}$ was also performed. In patients with stage I RC, high nuclear FBI-1 expression was significantly associated with poorer DFS time ( $\mathrm{P}=0.013$; Fig. 4C); however, no significance was observed following analysis of high nuclear FBI-1 and OS time (Fig. 4D). This could be due to the low positive rate and small sample size, since only 5 samples presented high nuclear FBI-1 staining in this subgroup of patients. In patients with stage II $\mathrm{RC}$, high nuclear FBI-1 expression was associated with poor DFS time $(\mathrm{P}=0.268$; Fig. $4 \mathrm{E})$ and $\mathrm{OS}$ time $(\mathrm{P}=0.300$; Fig. $4 \mathrm{~F})$; however the differences were not significant. In patients with stage III RC, high nuclear FBI-1 expression was significantly associated with poor DFS time $(\mathrm{P}=0.005$; Fig. $4 \mathrm{G})$ and $\mathrm{OS}$ time ( $\mathrm{P}=0.036$; Fig. 4H). However, cytoplasmic FBI-1 expression was not associated with DFS and OS times $(\mathrm{P}=0.645$ and $\mathrm{P}=0.982$, respectively; data not shown).

Following multivariable analysis, the significance remained following adjusting for sex, age, growth pattern, 

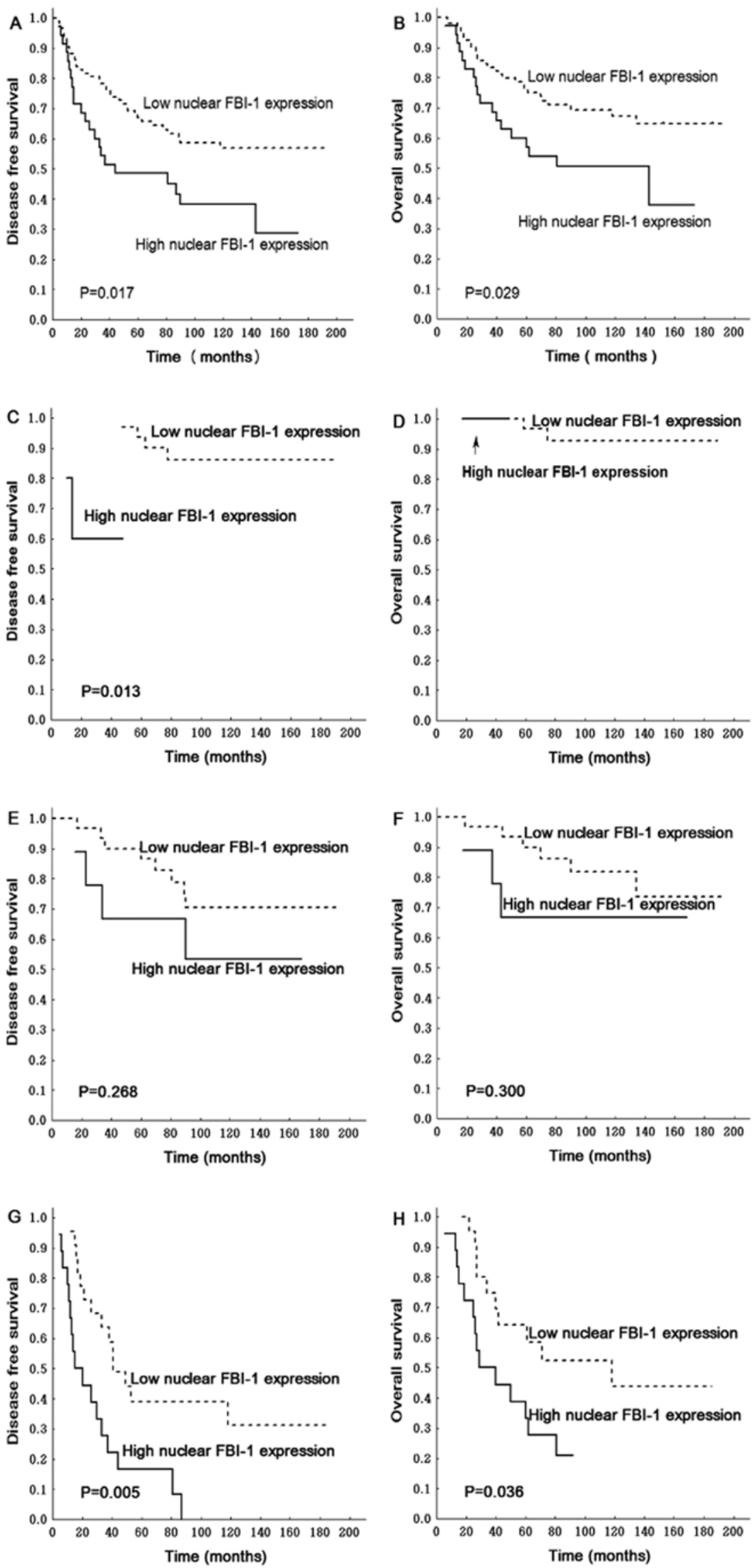

Figure 4. Association between tumor-node-metastasis stage of RC, and DFS and OS. Patients with stage I, II and III RC and high nuclear FBI-1 expression exhibited poorer (A) DFS and (B) OS. In patients with stage I RC, high nuclear FBI-1 was significantly associated with poorer (C) DFS, but no significance was observed with (D) OS. In stage II patients, nuclear FBI-1 expression was not associated with (E) DFS or (F) OS. In patients with stage III RC, high nuclear FBI-1 expression was significantly associated with poorer (G) DFS and (H) OS. DFS, disease-free survival; FBI-1, factor that binds to the inducer of short transcripts of the human immunodeficiency virus-1; OS, overall survival; RC, rectal cancer. 
Table III. Multivariate analysis of the association between nuclear FBI-1 expression and survival of patient with rectal cancer.

\begin{tabular}{|c|c|c|c|c|c|c|c|c|}
\hline \multirow[b]{2}{*}{ Variables } & \multicolumn{4}{|c|}{ Disease-free survival } & \multicolumn{4}{|c|}{ Overall survival } \\
\hline & Number & HR & $95 \% \mathrm{CI}$ & P-value & Number & HR & $95 \% \mathrm{CI}$ & P-value \\
\hline Nuclear FBI-1 & & & & 0.033 & & & & 0.025 \\
\hline Low & 82 & 1 & & & 82 & 1 & & \\
\hline High & 29 & 1.934 & $1.055-3.579$ & & 29 & 2.174 & $1.102-4.290$ & \\
\hline Sex & & & & 0.358 & & & & 0.447 \\
\hline Male & 65 & 1 & & & 65 & 1 & & \\
\hline Female & 46 & 0.764 & $0.429-1.360$ & & 46 & 0.780 & $0.411-1.479$ & \\
\hline Age, years & & & & 0.066 & & & & 0.018 \\
\hline$\leq 66$ & 42 & 1 & & & 42 & 1 & & \\
\hline$>66$ & 69 & 1.770 & $0.963-3.256$ & & 69 & 2.356 & $1.158-4.792$ & \\
\hline GP & & & & 0.113 & & & & 0.077 \\
\hline Expanding & 76 & 1 & & & 76 & 1 & & \\
\hline Invasive & 35 & 1.598 & $0.895-2.855$ & & 35 & 1.787 & $0.938-3.404$ & \\
\hline Differentiation & & & & 0.508 & & & & 0.828 \\
\hline High/moderate & 88 & 1 & & & 88 & 1 & & \\
\hline Poor & 23 & 0.788 & $0.388-1.597$ & & 23 & 0.921 & $0.437-1.942$ & \\
\hline Radiotherapy & & & & 0.077 & & & & 0.083 \\
\hline No & 67 & 1 & & & 67 & 1 & & \\
\hline Yes & 44 & 0.586 & $0.324-1.061$ & & 44 & 0.554 & $0.284-1.081$ & \\
\hline
\end{tabular}

The total number of cases was 111, and variations in numbers are due to incomplete data. CI, confidence interval; GP, growth pattern; HR, hazard ratio.

Table IV. Association between expressions of nuclear FBI-1 protein and other proteins.

\begin{tabular}{|c|c|c|c|c|c|c|}
\hline \multirow[b]{2}{*}{ Biological variables } & \multicolumn{3}{|c|}{ Non-radiotherapy group } & \multicolumn{3}{|c|}{ Radiotherapy group } \\
\hline & Number & $\mathrm{r}_{\mathrm{s}}$ & P-value & Number & $\mathrm{r}_{\mathrm{s}}$ & P-value \\
\hline p53 & 73 & -0.120 & 0.311 & 59 & -0.079 & 0.550 \\
\hline Wrap53 & 74 & -0.425 & $<0.001$ & 60 & 0.002 & 0.987 \\
\hline P73 & 65 & 0.332 & 0.007 & 46 & -0.048 & 0.754 \\
\hline $\operatorname{PPAR} \delta$ & 74 & -0.132 & 0.261 & 57 & -0.294 & 0.026 \\
\hline LOX & 75 & 0.234 & 0.043 & 59 & 0.213 & 0.106 \\
\hline $\mathrm{Ki}-67$ & 62 & -0.138 & 0.284 & 46 & -0.264 & 0.077 \\
\hline
\end{tabular}

Variations in numbers for different variables are due to incomplete data. LOX, lysyl oxidase; PPAR $\delta$, peroxisome proliferator-activated receptor $\delta ; r_{s}$, Spearman's correlation coefficient.

differentiation and RT [DFS time hazard ratio (HR), 1.934, 95\% confidence interval (CI), 1.055-3.579; OS time HR, 2.174, 95\% CI, 1.102-4.290; Table III].

Correlation between nuclear FBI-1 and biological variables. The present study analyzed the correlation between the expression of nuclear FBI-1 expression and of biological factors, including p53, Wrap53, p73, PPAR8, LOX and Ki-67, which were previously investigated in the same patient cohort (19-22). In the non-RT group, FBI-1 nuclear expression was positively correlated with the expression of p73 [Spearman's correlation coefficient $\left.\left(r_{s}\right)=0.332\right]$ and LOX $\left(r_{s}=0.234\right)$, but negatively correlated with Wrap53 expression $\left(r_{s}=-0.425\right)$ (Table IV). In the RT group, FBI-1 nuclear expression was negatively correlated with PPAR $\delta$ expression $\left(r_{s}=-0.294\right.$; Table IV). FBI-1 nuclear expression was neither correlated with Ki-67 or p53 expression in the non-RT and RT groups (Table IV).

\section{Discussion}

The present study investigated FBI-1 expression in patients with RC who underwent or not preoperative RT, and 
determined its association with patients' clinicopathological variables and biological factors. The results demonstrated that, compared with normal mucosa, FBI-1 was expressed in the cytoplasm and nucleus of RC samples, and that cytoplasmic FBI-1 expression was upregulated in RC samples from the non-RT and RT groups; however, nuclear staining was downregulated in these two groups. RT may therefore have no effect on FBI-1 expression. Furthermore, nuclear FBI-1 was positively associated with TNM stage $(\mathrm{P}=0.003)$ and distance recurrence $(\mathrm{P}=0.010)$. In patients with stage I, II or III RC, increased nuclear FBI-1 expression was associated with poorer DFS and OS times independent of sex, age, growth pattern, differentiation and RT.

With regards to the localization of FBI-1 protein in CRC, the results are contradictory. A previous study reported that FBI-1 is mainly expressed in the nucleus of colon cancer cells (24); however, other studies demonstrated that FBI-1 is predominantly expressed in the cytoplasm and partly in the nucleus of CRC cells $(13,14)$. The results from the present study provided further evidence that FBI-1 protein was localized in the cytoplasm and the nucleus of RC cells. This was also observed in other types of cancer, including HCC where FBI-1 is mostly expressed in the cytoplasm and rarely in the nucleus (25). The present study analyzed cytoplasmic and nuclear FBI-1 staining separately, and reported that, compared with normal mucosa, the expression of cytoplasmic FBI-1 and FBI-1 mRNA were upregulated, whereas nuclear FBI-1 expression was downregulated in $\mathrm{RC}$ cells. A possible reason for this discrepancy may be the sample investigated, since all samples from the present study were RC samples; however previous studies have included rectal and colon cancer samples. Increasing evidence reported that RC possesses numerous molecular markers and some characteristics of colon cancer $(26,27)$. Another possible reason may be the aberrant transport process of FBI-1 protein from the cytoplasm to the nucleus, which requires further investigation.

The results from the present study demonstrated that preoperative RT had no effect on FBI-1 expression in RC. The non-RT and RT groups were therefore combined in the further analyses. FBI-1 nuclear staining was positively associated with TNM stage and distant recurrence. Furthermore, patients with stage III and IV RC exhibited higher FBI-1 expression compared with patients with stage I and II RC, and patients with distant recurrence exhibited higher FBI-1 expression compared with those without distant recurrence (Table II). These results were in accordance with a previous study reporting that FBI-1 expression is positively associated with Dukes' stage in CRC (14). Although FBI-1 expression could be used as a prognostic biomarker in HCC and lung cancer $(5,6)$, no studies reported its prognostic significance in RC. To the best of our knowledge, the present study is the first to demonstrate that nuclear FBI-1 expression may serve as a prognostic factor in patients with $\mathrm{RC}$, in particular in patients with stage III RC.

As one of the most important oncogene regulators, FBI-1 has been implicated in numerous signaling pathways, including the ARF-MDM2-p53 (28), phosphoinositide 3-kinase/Akt signaling (29), Smad4 and TGF- $\beta$ (30), and myocyte enhancer factor 2D pathways (31). However, the pathway associated with FBI-1 in RC remains unclear. Zhao et al (14) reported that FBI-1 and p14ARF or p53 are not correlated, and that
FBI-1-knockdown in the colon cancer LoVo cell line did not affect p14ARF expression, which demonstrated that FBI-1 functions independently of the p14ARF-MDM2-p53 pathway. In the present study, no correlation was observed between FBI-1 and 553 expression, which further suggested that FBI-1 may exert its activity independently of the p14ARF-MDM2-p53 pathway. Of note, a negative correlation between FBI-1 and Wrap53 was reported, combined with a positive correlation between $\mathrm{p} 73$ and LOX in the non-RT group and a positive correlation with PPAR $\delta$ in the RT group. These results suggested that FBI-1 may regulate multiple genes and therefore affect RC development and progression. The underlying mechanisms of this pathway require further investigation.

Although the present study provided evidence that FBI-1 may participate in RC, there were a few limitations. Firstly, FBI-1 expression with or without preoperative RT should also be determined in RC cell lines. Secondly, the molecular mechanism underlying the role of FBI-1 in RC requires further examination. Further investigation using an RC cell line and animal model experiments is therefore required in order to explore the FBI-1 signaling network in RC.

In conclusion, the present study demonstrated that FBI-1 was highly expressed in RC samples and that nuclear FBI-1 may be an independent prognostic factor in patients with RC. Since FBI-1 was positively correlated with several biological factors, its role in RC may be complex.

\section{Acknowledgements}

The authors would like to thank Dr Sebastian Gnosa and Dr Johannes Stratmann (Linköping University, Sweden) for their technical help.

\section{Funding}

The present study was supported by the National Natural Science Foundation of China (grant no. U1204818; 2013), the Projects of Science and Technology in Henan Province (grant nos. 172102310064 and 201702195; 2017) and the Swedish Cancer Foundation (grant no. 3610-B06-11XCC; 2007).

\section{Availability of data and materials}

The datasets generated and analyzed during the present study are available from the corresponding author upon reasonable request.

\section{Authors' contributions}

CJW, HZ and XFS designed the study. CJW, CRC, HML and GA performed the experiments, data analysis and interpretation. YYZ, GA and IJ collected the samples and performed the clinical characterization of patients. CJW and XFS wrote the manuscript. All authors read and approved the final manuscript.

\section{Ethics approval and consent to participate}

The present study was approved by the Medical Ethics Committee of Linköping University. Written informed consent was obtained from each patient. 


\section{Patient consent for publication}

Not applicable.

\section{Competing interests}

The authors declare that they have no competing interests.

\section{References}

1. Yang Y, Li Y, Di F, Cui J, Wang Y and David Xu ZQ: Pokemon decreases the transcriptional activity of RAR $\alpha$ in the absence of ligand. Biol Chem 398: 331-340, 2016

2. Maeda T, Hobbs RM, Merghoub T, Guernah I, Zelent A Cordon-Cardo C, Teruya-Feldstein J and Pandolfi PP: Role of the proto-oncogene Pokemon in cellular transformation and ARF repression. Nature 433: 278-285, 2005.

3. Wang L, Li Q, Ye Z and Qiao B: Pokemon/miR-137 auto-regulatory circuit promotes the progression of renal carcinoma. Oncol Res: Apr 19, 2018 doi: 10.3727/096504018X15231148037228, (Epub ahead of print)

4. Jiang L, Siu MK, Wong OG, Tam KF, Lam EW, Ngan HY, Le XF, Wong ES, Chan HY and Cheung AN: Overexpression of proto-oncogene FBI-1 activates membrane type 1 matrix metalloproteinase in association with adverse outcome in ovarian cancers. Mol Cancer 9: 318, 2010.

5. Fang F, Yang L, Tao Y and Qin W: FBI-1 promotes cell proliferation and enhances resistance to chemotherapy of hepatocellular carcinoma in vitro and in vivo. Cancer 118: 134-146, 2012.

6. Zhao ZH, Wang SF, Yu L, Wang J, Chang H, Yan WL, Zhang J and $\mathrm{Fu} \mathrm{K}$ : Overexpression of Pokemon in non-small cell lung cancer and foreshowing tumor biological behavior as well as clinical results. Lung Cancer 62: 113-119, 2008.

7. Zhao Z, Wang J, Wang S, Chang H, Zhang T and Qu J: LncRNA CCAT2 promotes tumorigenesis by over-expressed Pokemon in non-small cell lung cancer. Biomed Pharmacother 87: 692-697, 2017.

8. Yi TJ and Wang P: The expression of Pokemon in endometrial carcinoma tissue and the correlation with mutant p53. Sichuan Da Xue Xue Bao Yi Xue Ban 47: 321-325, 2016 (In Chinese).

9. Jiao W, Liu F, Tang FZ, Lan J, Xiao RP, Chen XZ, Ye HL and Cai YL: Expression of the Pokemon proto-oncogene in nasopharyngeal carcinoma cell lines and tissues. Asian Pac J Cancer Prev 14: 6315-6319, 2013.

10. Aggarwal H, Aggarwal A, Hunter WJ III, Yohannes P, Khan AU and Agrawal DK: Expression of leukemia/lymphoma related factor (LRF/Pokemon) in human benign prostate hyperplasia and prostate cancer. Exp Mol Pathol 90: 226-230, 2011.

11. Zu X, Ma J, Liu H, Liu F, Tan C, Yu L, Wang J, Xie Z, Cao D and Jiang Y: Pro-oncogene Pokemon promotes breast cancer progression by upregulating survivin expression. Breast Cancer Res 13: R26, 2011.

12. Sartini D, Lo Muzio L, Morganti S, Pozzi V, Di Ruscio G, Rocchetti R, Rubini C, Santarelli A and Emanuelli M: Pokemon proto-oncogene in oral cancer: Potential role in the early phase of tumorigenesis. Oral Dis 21: 462-469, 2015.

13. Zhu M, Li M, Zhang F, Feng F, Chen W, Yang Y, Cui J, Zhang D and Linghu E: FBI-1 enhances ETS-1 signaling activity and promotes proliferation of human colorectal carcinoma cells. PLoS One 9: e98041, 2014.

14. Zhao Y, Yao YH, Li L, An WF, Chen HZ, Sun LP, Kang HX, Wang $\mathrm{S}$ and $\mathrm{Hu} \mathrm{XR}$ : Pokemon enhances proliferation, cell cycle progression and anti-apoptosis activity of colorectal independently of p14ARF-MDM2-p53 pathway. Med Oncol 31: 288 2014.

15. Kim SW, Yu K, Shin KS, Kwon K, Hwang TS and Kwon OY: Low-dose radiation suppresses Pokemon expression under hypoxic conditions. Z Naturforsch C 69: 68-74, 2014.
16. De Rosa M, Pace U, Rega D, Costabile V, Duraturo F, Izzo P and Delrio P: Genetics, diagnosis and management of colorectal cancer (Review). Oncol Rep 34: 1087-1096, 2015.

17. Wang X, Zheng B, Lu X, Bai R, Feng L, Wang Q, Zhao Y and He S: Preoperative short-course radiotherapy and long-course radiochemotherapy for locally advanced rectal cancer: Meta-analysis with trial sequential analysis of long-term survival data. PLoS One 13: e0200142, 2018.

18. Hermanek P and Sobin LH (eds): TNM Classification of Malignant Tumours, 4th edition. Geneva: International Union Against Cancer, 1987.

19. Pfeifer D, Gao J, Adell G and Sun XF: Expression of the p73 protein in rectal cancers with or without preoperative radiotherapy. Int J Radiat Oncol Biol Phys 65: 1143-1148, 2006.

20. Yang L, Zhang H, Zhou ZG, Yan H, Adell G and Sun XF: Biological function and prognostic significance of peroxisome proliferator-activated receptor $\delta$ in rectal cancer. Clin Cancer Res 17: 3760-3770, 2011.

21. Zhang H, Wang DW, Adell G and Sun XF: WRAP53 is an independent prognostic factor in rectal cancer- a study of Swedish clinical trial of preoperative radiotherapy in RC patients. BMC Cancer 12: 294, 2012.

22. Liu N, Cox TR, Cui W, Adell G, Holmlund B, Ping J, Jarlsfelt I, Erler JT and Sun XF: Nuclear expression of lysyl oxidase enzyme is an independent prognostic factor in rectal cancer patients. Oncotarget 8: 60015-60024, 2016.

23. Livak KJ and Schmittgen TD: Analysis of relative gene expression data using real-time quantitative PCR and the 2(-Delta Delta C(T)) method. Methods 25: 402-408, 2001.

24. Choi WI, Jeon BN, Yun CO, Kim PH, Kim SE, Choi KY, Kim SH and Hur MW: Proto-oncogene FBI-1 represses transcription of p21CIP1 by inhibition of transcription activation by $\mathrm{p} 53$ and $\mathrm{Sp} 1$. J Biol Chem 284: 12633-12644, 2009.

25. Lin CC, Zhou JP, Liu YP, Liu JJ, Yang XN, Jazag A, Zhang ZP, Guleng B and Ren JL: The silencing of Pokemon attenuates the proliferation of hepatocellular carcinoma cells in vitro and in vivo by inhibiting the PI3K/Akt pathway. PLoS One 7: e51916, 2012.

26. Ichimasa K, Kudo SE, Miyachi H, Kouyama Y, Hayashi T, Wakamura K, Hisayuki T, Kudo T, Misawa M, Mori Y, et al: Comparative clinicopathological characteristics of colon and rectal T1 carcinoma. Oncol Lett 13: 805-810, 2017.

27. Tamas K, Walenkamp AM, de Vries EG, van Vugt MA, Beets-Tan RG, van Etten B, de Groot DJ and Hospers GA: Rectal and colon cancer: Not just a different anatomic site. Cancer Treat Rev 41: 671-679, 2015.

28. Maeda T, Hobbs RM and Pandolfi PP: The transcription factor Pokemon: A new key player in cancer pathogenesis. Cancer Res 65: 8575-8578, 2005 .

29. Mak VC, Wong OG, Siu MK, Wong ES, Ng WY, Wong RW, Chan KK, Ngan HY and Cheung AN: FBI-1 is overexpressed in gestational trophoblastic disease and promotes tumor growth and cell aggressiveness of choriocarcinoma via PI3K/Akt signaling. Am J Pathol 185: 2038-2048, 2015.

30. Yang Y, Cui J, Xue F, Zhang C, Mei Z, Wang Y, Bi M, Shan D, Meredith A, Li H and Xu ZQ: Pokemon (FBI-1) interacts with Smad4 to repress TGF- $\beta$-induced transcriptional responses. Biochim Biophys Acta 1849: 270-281, 2015.

31. Kong J, Liu X, Li X, Wu J, Wu N, Chen J and Fang F: Pokemon promotes the invasiveness of hepatocellular carcinoma by enhancing MEF2D transcription. Hepatol Int 10: 493-500, 2016.

This work is licensed under a Creative Commons Attribution-NonCommercial-NoDerivatives 4.0 International (CC BY-NC-ND 4.0) License. 